\title{
A 'disjunct' in the linguistic landscape: Messages about food and nutrition in Indonesian school environments
}

\author{
Lesley Harbon ${ }^{1}$ and Sisilia Setiawati Halimi ${ }^{2} *$ \\ ${ }^{1}$ School of International Studies and Education, Faculty of Arts and Social Sciences, University of Technology Sydney, \\ Building 10, Broadway NSW 2007, Australia \\ ${ }^{2}$ Department of Linguistics, Faculty of Humanities, Universitas Indonesia, Kampus UI, Depok 16424, Indonesia
}

\begin{abstract}
In Indonesia's schoolscapes, messages regarding food and nutrition abound. The researchers conducted descriptive, evaluative research on the nature and scope of the linguistic landscape around 20 primary school grounds in Jakarta and Depok education districts. The purpose of this study was to gather (digitally) and analyze food/nutrition signs/texts in order to determine which languages are represented in which places, and the kinds of messages for each language. As well, the study explored other non-food images relating to health found in these schoolscapes. Data were analysed using open and axial coding. The study found that the majority of the texts and images are found to be in Indonesian and only a small percentage are in Sundanese, Arabic, Japanese and English. Texts relating to food and nutrition were found inside and outside the school environments. Each language was responsible for a particular type of message. Official (top-down) messages inside the schoolscapes advocate for healthy food and nutrition. Texts found outside the schoolscapes convey a variety of messages, healthy and otherwise: from food labels, and flavor, to cigarette advertising. There is a 'disjunct' between the overtly health-oriented linguistic landscape inside the school perimeter and the less healthy linguistic landscape outside the schoolscapes, an issue which may be of concern to schools and their communities.
\end{abstract}

Keywords: Food; nutrition; school; linguistic landscape; Indonesia

\begin{tabular}{|c|c|c|}
\hline $\begin{array}{c}\text { First Received: } \\
19 \text { September } 2018 \\
\text { Final Proof Received: } \\
\text { 27 January } 2019 \\
\end{array}$ & $\begin{array}{c}\text { Revised: } \\
\text { 19 December } 2018\end{array}$ & $\begin{array}{c}\text { Accepted: } \\
\text { 26 December } 2018 \\
\text { Published: } \\
\text { 31 January 2019 }\end{array}$ \\
\hline $\begin{array}{l}\text { How to cite (in APA style): } \\
\text { Harbon, L., \& Halimi, S. S. (2019 } \\
\quad \text { food and nutrition in Indonesi } \\
\quad \text { Linguistics, } 8,620-631 \text {. doi: } 1\end{array}$ & $\begin{array}{l} \\
\text { disjunct' in the lin } \\
\text { hool environment } \\
\text { 509/ijal.v8i3.1526 }\end{array}$ & $\begin{array}{l}\text { ic landscape: Messages about } \\
\text { lonesian Journal of Applied }\end{array}$ \\
\hline
\end{tabular}

\section{INTRODUCTION}

Indonesia is, like all other countries, concerned with child health and nutrition and the way this is linked to educational achievement. Julia, Van Weissenbruch, Prawirohartono, Surjono, and Delamarre-Van de Waal (2008) conducted a study tracking body mass index of Indonesian children through to adolescence and found that the prevalence of overweight and obesity increases as children grow into adolescence. An earlier study (Julia, Van Weissenbruch, Delamarre-van de Waal, \& Surjono, 2004) had examined stunting, overweight and obesity in urban and non-urban poor and non-poor, finding that wasting was associated with poverty, and obesity was associated with prosperity. Similarly, there are related studies regarding good food and nutrition in Australian children (see Rangan et al., 2012; Rangan, Kwan, Louie, Flood, Gill 2011). As Behrman says (1996, p. 23),

Better health and nutrition are positively associated with gains in schooling in many areas: enrolment at younger ages, less grade repetition, less absenteeism, more grades completed, and better performance on test scores. Recent surveys conclude that empirical studies constitute strong evidence showing that health and nutrition influence children's success in school.

\footnotetext{
* Corresponding Author

Email:sshalimi@gmail.com
} 
Grantham-McGregor et al. (2007, p. 60) note that "many children younger than 5 years in developing countries are exposed to multiple risks, including poverty, malnutrition, poor health, and unstimulating home environments, which detrimentally affect their cognitive, motor, and social-emotional development."

"Linguistic landscapes" research is relatively new in the area of applied linguistics (Backhaus, 2007), and is being applied to fields such as architecture, advertising, and education. The linguistic landscape is defined as the written and spoken texts and images in any landscape, including public spaces. Ben-Rafael, Shohamy, Amara, and Trumper-Hecht (2006) consider society to be symbolically constructed in the linguistic landscapes of public places. Shohamy and Gorter (2008, p. 314) write that "public space is an area that is negotiated and contested; and therefore, it is not neutral." They further state that a focus on linguistic landscapes shows what intentions are "embedded in societies and situated in humanistic, social, and political ecology of those who share, form, influence and are influenced by it."

According to Kallen (2010, p. 41), "studies of the linguistic landscape generally start from the assumption that signage is indexical of more than just the ostensive message of the sign". The messages/texts we find in the linguistic landscape have the potential to be powerful didactic devices, impacting what we know and how we respond to an issue.

Linguistic landscape research is increasingly allowing the comment to be made on societal issues. Barni, Machetti, Kolyva, and Palova (n.d), for example, studied the similarities and differences of linguistic landscapes in European cities. School-aged children too can be addressed or not addressed by different visual or written texts in the linguistic landscape. Linguistic landscape research in schooling contexts is still rare; for example, Tafoya's (2002) examination of the languages in existence in Californian schools. Similarly, Reagan (2002) produced a larger map of the linguistic landscape across US schools in general.

In Indonesia, very little linguistic landscape research related to school-aged children has been undertaken (see for example da Silva, 2014), although some larger projects have been undertaken on Indonesia's border in Timor-Leste (Macalister, 2012; Taylor-Leech, 2012). Da Silva's (2014) doctoral research focused on the languages in billboard advertising in Indonesia's capital city, Jakarta. No linguistic landscape research has been carried on until now focusing on texts evident in school landscapes in Indonesia. Our research reported here recounts the situation of a microcosm within a city: that is inside and at the perimeter of different primary schools where linguistic landscape signage is prolific. With reference to Backhaus' (2007, p. 1) study, we also focus on "the written medium: the language of the signs... the myriad of written messages on public display" in these primary school environments. In addition, as Backhaus (2007, p. 57 ) focuses on the "linguistic landscaping by whom" question, we also agree with Backhaus' opinion that the "originator or source of the sign" (2007, p. 57) should importantly be considered, as the polarities of official/non-official, top-down/bottom-up, or even municipal-governmental/commercial authoring are in evidence.

In addition, we also follow Landry and Bourhis' (1997) conceptualisation of a linguistic landscape that particularly focuses on the public signs placed by, and those who interact in the primary school communities. The public space we explore can, therefore, be understood as a public space accessed by a subset of a community, although an amount of the signs inside and around the perimeter of these 20 Indonesian primary schools can be viewed by all who pass by. Our analysis of the signs at the perimeters of these primary schools, plus the signs inside the semi-public spaces of the primary schools, frequented by education officials, parents and friends in the community, therefore, constitute a valid parameter around which we make our statements about the linguistic landscape.

According to Fieldhouse (1995, p. x) "human beings the world over share a common need to meet certain fundamental conditions for survival. One of these needs is the securing of an adequate diet which will provide energy and the various nutrients necessary for metabolic functioning." This nutrition comes from our food and beverage intake and is closely related to health. We have used the definition of food according to the Presiden Republik Indonesia declaration (2004, p. 5) as "anything originating from biological and water sources, either processed or unprocessed, designated as food or beverage for human consumption, including food additives, food raw materials and other materials used in the process of preparing, processing and/or making food or beverage." This study has produced informative data regarding the "linguistic landscapes" in twenty of Indonesia's schoolscapes.

Educational policymakers, advertising groups, health, medical and agriculture experts will be able to take useful information from the findings of this examination of the linguistic landscape. This innovative approach has the potential to serve as a model for similar fields of research. The "educational" aspects of this linguistic landscape research in the context of Indonesia's schooling systems also have the potential to provide a link to agriculture and medical research. Health/medical researchers in Indonesia may well be able to intersect or even correlate their own findings with findings from this project, to gain greater insight into the impact of poor nutrition on school performance.

Systematic gathering of photographs in these schoolscapes resulted in the compilation and storage of a corpus of data representing the texts and images classified as pertaining to both 'food', 'nutrition' and 'health' located in the primary school linguistic landscapes. Other texts and images were gathered in those same landscapes which were considered as not pertaining to 'food' and 'nutrition'. 
The project was framed by two research questions: (1) Which languages are represented in the schoolscapes? And (2) Where is each language found, what images are represented and what message does each represent?

\section{METHOD}

In order to obtain the texts/images from every school, a digital camera was used by the researchers' assistants to capture images in these schoolscapes. The data were then numbered and stored systematically. The data were then classified using the food classification system, Food Safety and Standards Authority of India (FSSAI) (2011). An India classification system was considered a "like" context regarding the cuisine compared to Indonesia's spices, salts, sweets and oils. In addition, the type of the artefact, the language used, the specific location, visibility and text keywords were identified and recorded. By "text keywords" we mean, the "actual" words written in text on the sign, such as "delicious" describing a chocolate cookie, or if no written text was included on the object, the researchers labelled the object with a suitable keyword, such as "stop sign" where no text, rather a stop sign universal image was photographed.

After the classification was completed, open and axial content analysis was conducted to obtain the patterns of information in the text/images related to food, nutrition and health (Böhm, 2004, p. 271). Open coding is the process of breaking down the data into separate units of meaning (Goulding, 1999). It takes place at the beginning of a study. The main purposes of open coding are to conceptualize and label data (Brown, Stevenson, Troiano, \& Schneider, 2002). Through systematic analysis and constant comparison of data, the next stage is to reduce the number of codes and to collect them together (the axial phase) in a way that shows a relationship among them. This stage relates to axial coding and the creation of concepts (Goulding, 1999).

\section{FINDINGS AND DISCUSSION}

The results and discussion for this study are presented through the frame of the two research questions.
Although more than 400 texts and images were gathered in the 20 linguistic landscapes, the total images related to food, nutrition and health used for the purpose of this study were 187 , as many of the images were duplications.

\section{Research Question 1: Which languages are represented in the schoolscapes? \\ Relating to research question 1 , the study shows that the majority of the texts and images (94\%) are found to be written in Indonesian, and only a small percentage of the data are written in Sundanese (less than 1\%), Arabic (less than 1\%), Japanese (less than 1\%) and English (3\%).}

Figure 1 shows a poster about health and nutrition, written in Indonesian, found on a classroom wall. It is typical of many of the official government produced curriculum materials provided to teachers in schools who need to teach health and nutrition.

In one school in Depok, there were two handcrafted posters designed by the students on the topic of food and nutrition written in the Sundanese language, the language of the peoples of West Java. Figure 2 shows how Sundanese is used to label nutritious food.

Sundanese is a regional language for the people in West Java. Sundanese is a language widely used by people who live in this area. In that particular school, Sundanese is also taught as a heritage language, one aspect of the regional educational policy to preserve local languages.

Only a small percentage of the food, nutrition and health images in the schoolscapes are written in English, Japanese or Arabic. Japanese is, like English, a language of international trade and commerce, and appears on some packaging of imported snack items (see Figure 3). English and Arabic are both found on a large advertising banner in one schoolscape. Figure 4 shows English used with nothing more in mind than to provide a short, sharp message about the effects of enjoying fruit juice, and the 'original' or 'real' fruits used to make the juice. Arabic is found in the "halal" sign at the bottom right of the poster, indicating the juice is produced through an officially/religiously endorsed company.

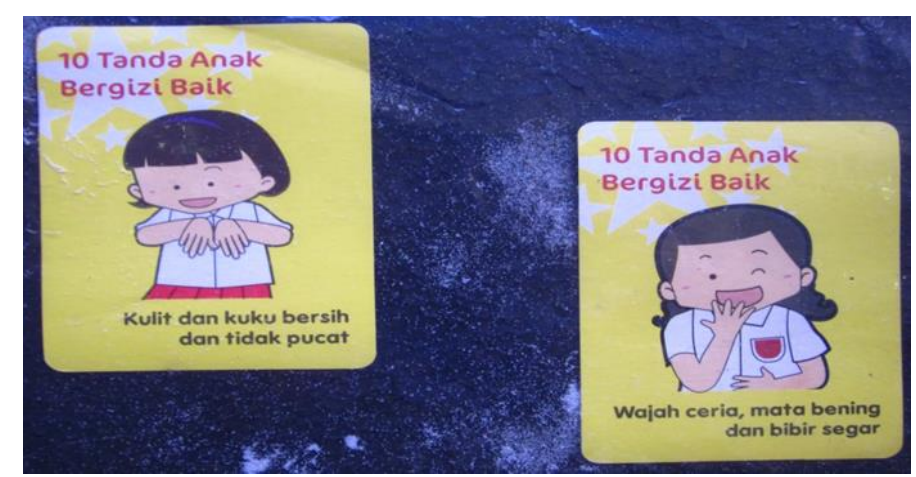

Figure 1. Wall posters in a classroom - Ten signs of Good Child nutrition: clean, not pale, skin and nails, bright face, clear eyes, and moist lips 


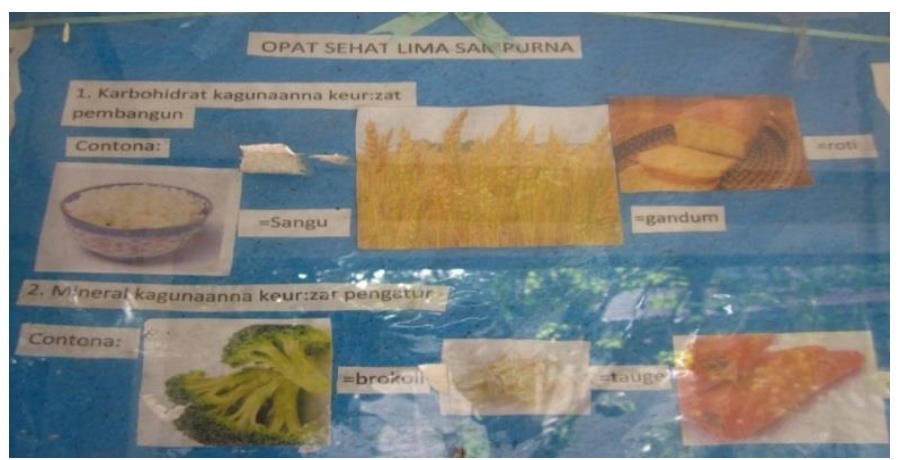

Figure 2. Student-produced poster of nutritious food (Sundanese) - Four Healthy Five Perfect Food (The 4 healthy food are carbohydrates (usually represented by rice), protein (usually represented by meat or fish), vegetables (usually represented by green vegetables), and fruits. The 5th "food", which makes the nutrition program "perfect" is milk.

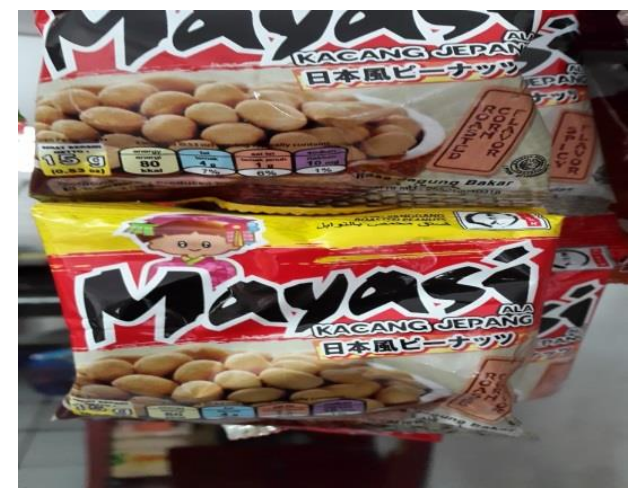

Figure 3. Japanese Peanuts

Only a small percentage of the food and nutrition data in the linguistic landscape is written in English. This is not surprising because Indonesian is used as the language of instruction in schools although the number of texts and images written in English is increasing. Figure 4 is an example of texts written in English.
When noting the research of Landry and Bourhis (1997) regarding the power and status of one language over the other, it might be possible to conclude that information about food and nutrition is rightly within the responsibility of the government of Indonesia, and through its official language, Indonesian (94\%).

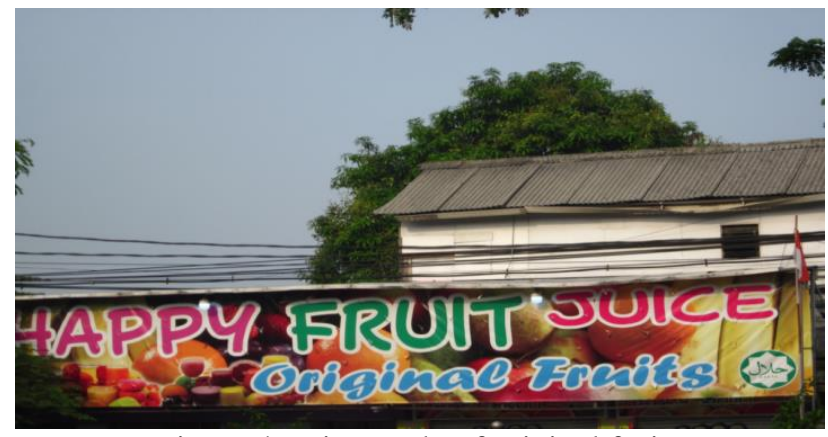

Figure 4. Juice made of original fruits

Research Question 2: Where is each language found, what images are represented and what message does each represent?

Relating to the second research question, digital images inside and outside school grounds were categorized into the following groups for data reduction purposes.

There were 187 images collected for the purpose of this study. They consist of 19 posters, 11 leaflets, 35 cards, 30 food display signs, 25 roadside food stall signs, 16 food menus, 11 banners, 10 labels on large boards, 18 backdrops, 6 handmade posters, 4 students' creative illustrations/ drawings, and 2 wall calendars.
Figures 5, 6, 7 and 8 show a range of these images. All five languages (Indonesian, Sundanese, Japanese, English, and Arabic) are found at least once in this range of images.

Figure 5 shows a small poster that advertises ice cream in one of the school canteens. It is written in English and Indonesian.

Figure 6 shows a large wall poster for the classroom wall; another example of official government education department endorsed curriculum materials. This kind of poster is written in Indonesian. 


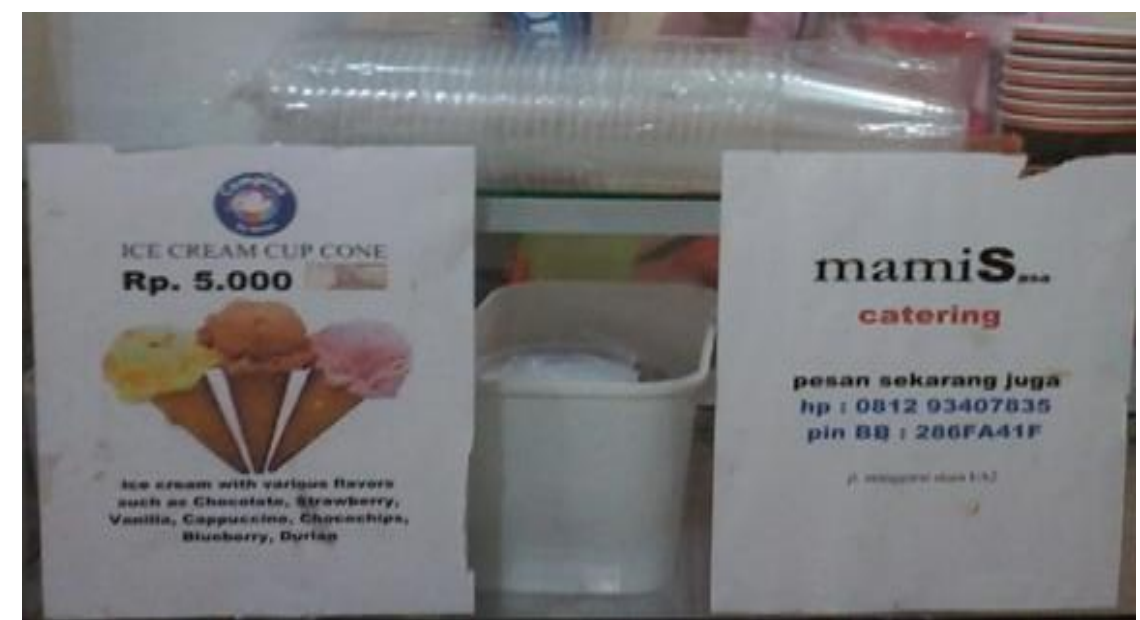

Figure 5. English and Indonesian signage on a canteen counter selling ice creams

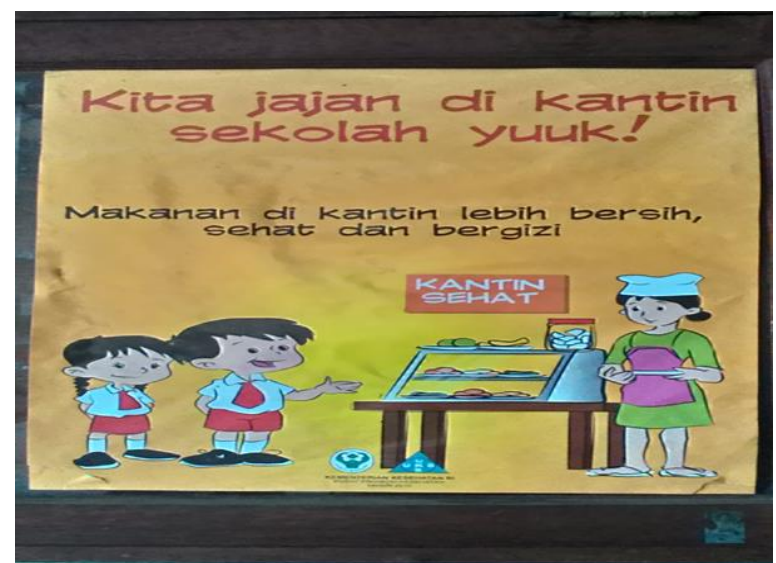

Figure 6. Let's buy snacks in our school canteen! The food in the school canteen is cleaner, healthier and more nutritious. Healthy Canteen.

Figure 7 is an example of a food display - a range of snack foods displayed for sale at a school canteen. Languages evident in this display are English (cheese) and Indonesian (50 tahun - terus pacu semangatmu - 50 years, keep up your spirits).
Figure 8 is an example of a health campaign in a schoolscape. It also shows a Tupperware (a plastic food container multinational company) advertisement, which contains an educational message. This kind of health campaign from various health and food products is written in Indonesian.

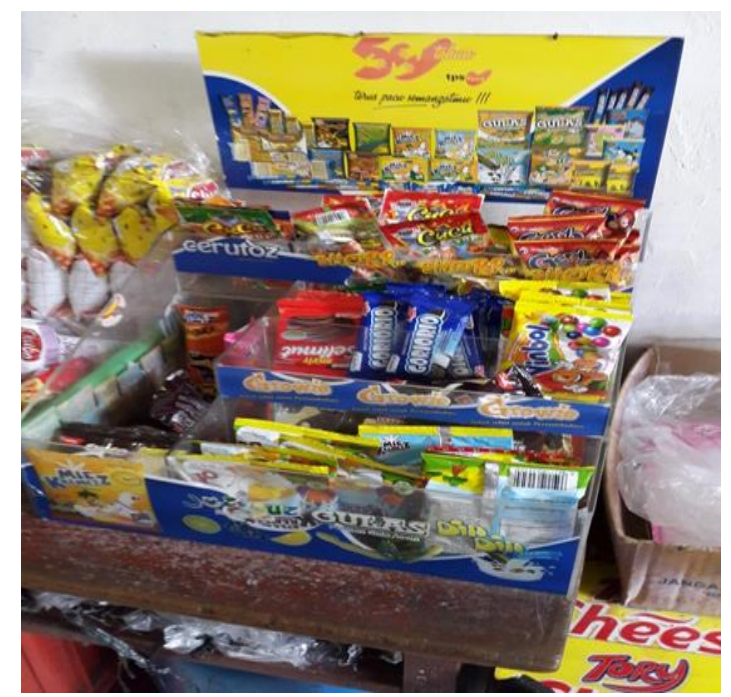

Figure 7: a range of snack foods displayed for sale at a school canteen. 


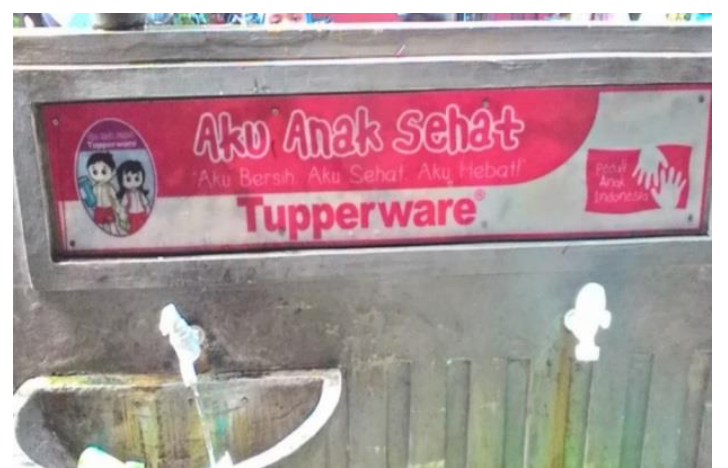

Figure 8. I'm a Healthy Child: I'm Clean, I'm Healthy, I'm Fabulous - Tupperware - Caring for Indonesian Children.

The various images gathered (examples in Figures 1 - 8) were collected inside and outside the school perimeters, and inside the schools were photographed on walls, gates, doors, hanging from ceilings, placed at water-fountains, and outside the school gates were on roadside signs, or displayed on or around food vendors' stalls.

As mentioned earlier, images were recorded in the schoolscapes for foods based on the India food classification system proposed by the FSSAI (2011) and classified into 8 categories: dairy products; fats, oils and fat emulsion; edible ices; meat and meat products, including poultry and game; beverages; ready-to-eat savories; prepared foods; and substances added to food. Text keywords allowed labels to be affixed to each image. The 8 categories are found in the images collected from the inside and outside school perimeters. There were 70 images that are related to food and nutrition. They consist of 8 images related to dairy products; 4 images related to fats, oils and fat emulsion; 6 images related to edible ices; 8 images related to meat and meat products; 9 images related to beverages; 14 images related to ready-to-eat savories; 9 images related to prepared foods and 12 images related to substances added to food. Figure 5 is an example of edible ices, and Figure 7 is an example of ready-to-eat savories.
Figure 5 is an example of edible ices found in the environments of some schools in Indonesia. The ice cream is home-made and often contains a lot of sugar and arguably not healthy for students. Ice cream is commonly found in schools in Indonesia. This picture is taken from one of the school canteens in a Jakarta school.

Figure 7 shows the savoury snacks sold in one Jakarta school canteen that sells savoury snacks and beverages. Again, most school canteens in Indonesia sell such snacks. Students can buy savoury snacks that contain less-healthy ingredients, as well as chocolates, candy and highly sugared beverages.

As can be seen in Figure 1, there are also artefacts that do not contain food images; rather they contain texts related to food and nutrition. In Figure 1 the cards explain the signs of a well-nourished child. The first card says that a well-nourished child has darker skin and nails (not pale). The second card says that a wellnourished child has a cheerful face, clear eyes and moist lips. There are 10 signs of a well-nourished child, and they are all explained in 10 different cards. This kind of text is usually sent to schools by the Indonesian Primary Education Directorate.

Some of the texts and images related to food and nutrition were also found outside school buildings, as can be seen in Figure 9.

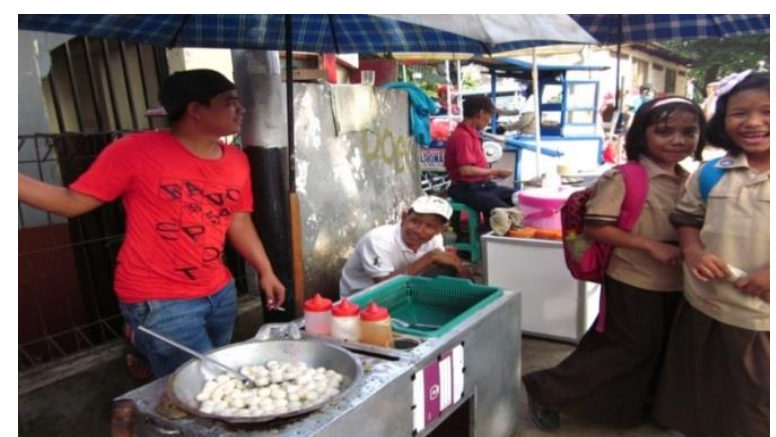

Figure 9: Example of images related to food sold outside school building

Figure 9 shows the food vendors outside the school compound. They sell various kinds of food, and they can be found in almost every school in Indonesia. Unfortunately, schools do not pay much attention to the quality of the food, and many of the food vendors do not sell nutritious food, and they do not pay attention to food hygiene. As can be seen in Figure 9, the food sold is fried in oil, and the oil for frying is rarely freshly replaced.

The findings of the study also demonstrate some texts and images not related to food and nutrition. There are 117 texts and images that belong to this group. 
These include texts and images related to health campaigns as can be seen in Figure 8.

It is evident that commercial businesses sponsor various health campaigns that can be found inside the schoolscapes. An example of such products and their wider campaigns include Frisian Flag (long-life or powdered milk) and Tupperware (hygienic plastic food storage containers) whose products are related to students and schools' needs. This can be seen in Figure 8 and Figure 10. Figure 10 shows that Frisian Flag, a company that produces milk, sponsors a health campaign that explains the importance of eating balanced nutritious food which consists of 4 different healthy food types (staple food, meat/fish, vegetable and fruit) plus milk. Tupperware sponsors a health campaign related to the importance of washing hands (Figure 8). There are various companies participating in health campaigns like these ones.

From the photographic evidence (written texts and picture/photograph/illustrated texts), we can conclude that there is solid evidence:

1. of both top-down (official, governmental) and ground-up (local, community) information in written and picture/illustrated texts about good food, nutrition and health;
2. that the message about food and nutrition is delivered through a higher-level message about "good food and nutrition" from the school canteen;

3. that the message about health is delivered through a higher-level message from the government; and

4. that the school canteen and foods for sale outside the school gates sell unhealthy food.

With these findings, the researchers' answers to research question 2 are multiple. First, some of the texts and images of food and nutrition in the linguistic landscapes are officially endorsed curriculum materials. One of the topics in primary school curriculum is about "Healthy Food"; therefore, schools encourage students to buy food in their schools' canteens where schools claim to provide clean, healthy and nutritious food as indicated in the poster (Figure 6).

In addition to this, there is also a text that provides students with some information that explains why students are not allowed to buy food arbitrarily (see Figure 11). This information is also part of the school materials that students have to learn. Posters and texts like this one are around schools to remind students of what they have learned in class.

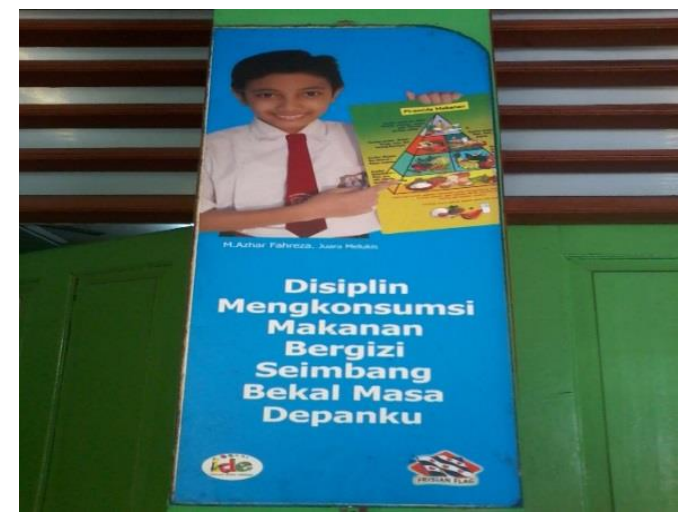

Figure 10. Being disciplined to eat only balanced nutritious food is your storage for the future

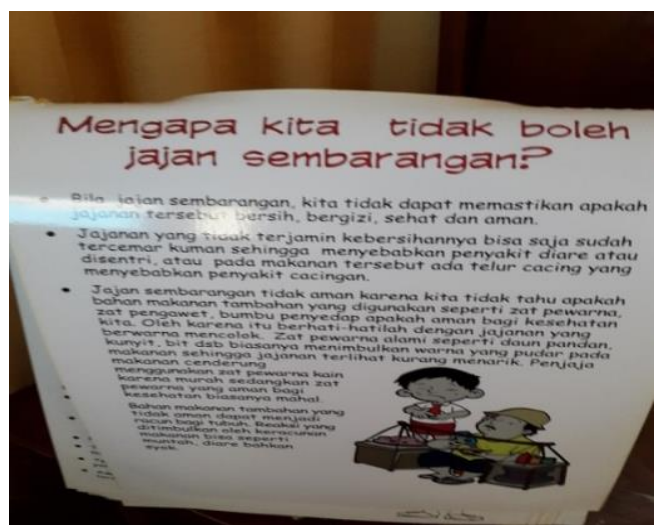

Figure 11. Example of texts endorsed by curriculum materials

Second, some of the texts and images are "healthy" messages with evidence of embedded "good" food and nutrition messages as can be seen in Figure 2. It informs students of the importance of eating balanced nutritious food as a provision for their future. This poster was made by the students as part of the curriculum materials. Another example can be seen in Figure 12. 


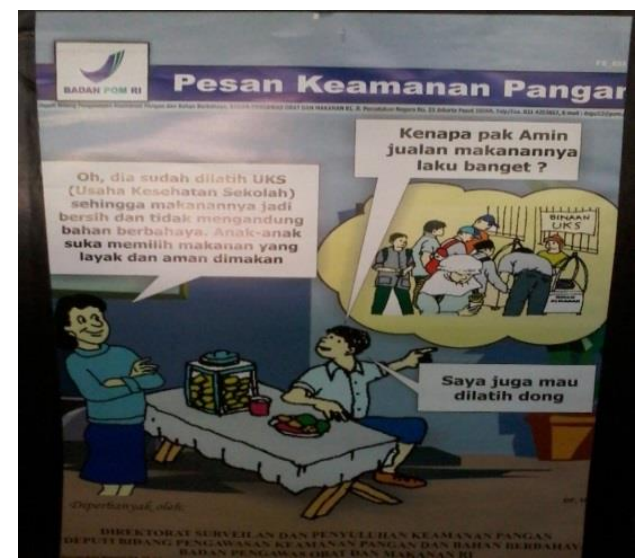

Figure 12. Example of texts with embedded "good" food and nutrition message

Figure 11 explains the importance for food vendors in school canteens to join a training held by health school unit so that they will only sell clean food that does not contain dangerous food substances.

Third, some images and texts are authentic texts/images which are not officially endorsed and show a reality contrary to the "healthy" messages found in the linguistic landscapes around the perimeters of primary schools in Jakarta and Depok. Figures 7, 9, and 13 show the common images found in every school in both Depok and Jakarta. While the texts/images found in schools" walls or noticeboards contain "healthy" messages, the reality shows that students are actually exposed to a lot of unhealthy food in the school compound, inside and outside the school building. Figure 13 shows one of the students' favourite snacks, fried macaroni. It is considered unhealthy food because the oil used for frying macaroni is often used many times so that it becomes dirty - even dangerous - for our health. In addition, to make the food more delicious, the food vendor usually uses additives -- substances which are considered as "unhealthy".

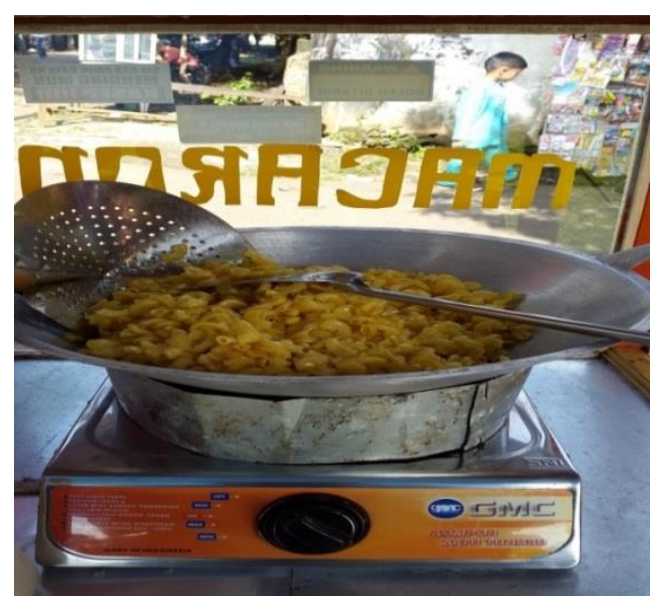

Figure 13. Example of authentic images around school building that is not officially endorsed

As explained earlier, canteens in different schools in this study always sell ready-to-eat savouries, candies, chocolates, peanuts and beverages (see Figure 7) containing a lot of sugar and "unhealthy" substances. Figure 14 shows that the place where students buy food outside the school building is not clean and students buy food without paying attention to "healthy" messages in their school buildings.

Figures $1-14$ show that there is a contradiction in school linguistic landscapes. Although the messages in the classroom walls, corridor walls and notice boards talk about nutritional value, balanced eating, and healthy foods, these top-down messages are not consistent with the foods found in the schools' canteens and foods/snacks available immediately outside the school grounds with the snack-food sellers, such as the sweet, sugary, salty foods containing saturated fats. Messages about good food and nutrition inside the schoolgrounds (e.g., the classrooms and corridor walls, the canteen) are not the same, and neither are the messages about good food and nutrition found outside the school grounds at the food sellers' mobile stalls.

The findings of the study also demonstrate some texts found on shop-awnings that advertise cigarettes and other products as can be seen in Figures 15 and 16 .

The banner, with English (Dunhill Mild) and Indonesian (New/ 16 pieces or 20 pieces, Warning: Smoking Kills You) is provided free to the stall holder whose stall is located directly opposite the school gate, and frequented by school-aged children on their journeys to and from school as can be seen in Figure 15. 


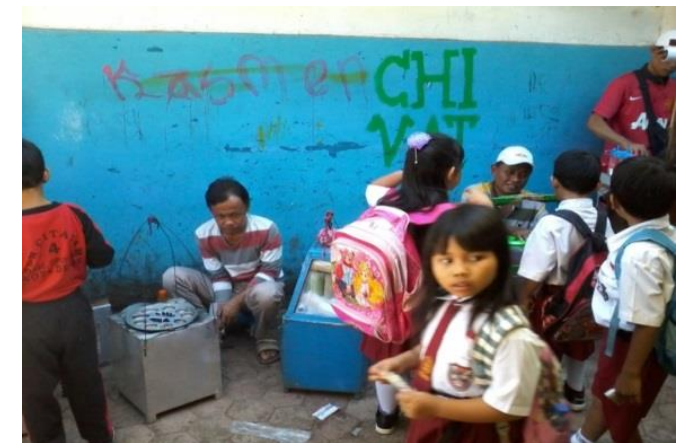

Figure 14. Authentic but not officially-endorsed food vending outside the school building

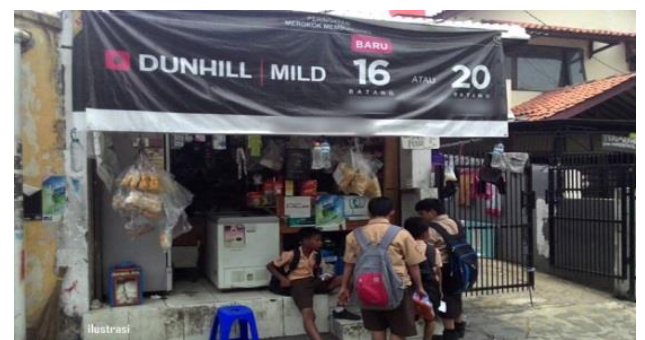

Figure 15. A cigarette advertising banner

Figure 16 does not advertise "unhealthy" products, but it is an advertisement, just the same. It advertises Surga (Heaven) Perfume, and it was found on an advertising awning outside a shop opposite a school. There are many images of this kind around school buildings in both cities.

The findings of this study relate to GranthamMcGregor et al.'s (2007, p. 60) concern that "many children younger than 5 years in developing countries are exposed to multiple risks, ...": the evidence suggested in this linguistic landscape snapshot study. The findings show that the linguistic landscapes around schools have many texts related to food, nutrition and health campaigns (89\%), yet also some cigarette and other products advertising (11\%). The various languages convey messages for different purposes. Indonesian as the main language used is the language of curriculum delivery, Arabic relates to the religious preparation of food, Sundanese, Japanese and English relate to other aspects of food, health, nutrition and life.

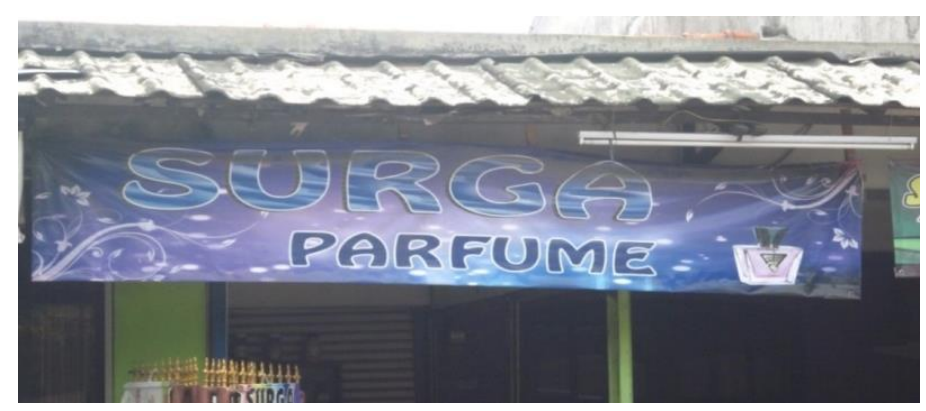

Figure 16. A perfume advertising banner

\section{CONCLUSION}

The texts and images gathered immediately outside the school perimeters indicate less evidence of notions of 'food and nutrition for good health'. There appears to be a 'disconnect' between the overtly good health-oriented linguistic landscape inside the school perimeter and the 'less healthy' linguistic landscape outside the school community.

The results point to a need for upscaling the project, to examine more urban and rural contexts throughout Indonesia and neighbouring countries to gather evidence about risks to children in the region more generally. The findings are important for education authorities in Indonesia, providing them with more information about the linguistic landscape of schools, potentially assisting the education authorities to participate in the nation's wider campaigns to combat the rise in obesity, diabetes and cardiovascular disease, described by Julia et al. (2008) as more prevalent as children grow into adolescence, by encouraging community dialogue about 'good health via good food and nutrition'.

\section{ACKNOWLEDGEMENT}

The authors acknowledge the funding of this research by the Australia Indonesia Centre, see:

http://australiaindonesiacentre.org/ 


\section{REFERENCES}

Backhaus, P. (2007). Linguistic landscapes: A comparative study of urban multilingualism in Tokyo. Clevedon: Multilingual Matters.

Barni, M., Machetti, S., Kolyva, K. \& Palova, R. (n.d). Conference presentation at International Conference the Future of Education. Retrieved online 12 September 2016, from:

https://conference.pixelonline.net/FOE/files/foe/ed0004/PPT/0896SLA557-PPT-FOE4.pdf

Behrman, J.R. (1996). The impact of health and nutrition on education. The World Bank Research Observer, 11(1), 23-37.

Ben-Rafael, E., Shohamy, E., Amara, M.H., \& Trumper-Hecht, N. (2006). Linguistic landscape as symbolic construction of the public space: The case of Israel. In D. Gorter (Ed.), Linguistic landscape: A new approach to multilingualism (pp. 7-30). Clevedon: Multilingual Matters.

Böhm, A. (2004). Theoretical coding: Text analysis in grounded theory. In U. Flick, E. Kardorff, \& I. Steinke, (Eds.), A Comparison to qualitative research (pp. 270-275). London: Sage Publications.

Brown, S. C., Stevenson, R. A., Troiano, P. F. \& Schneider, M. K. (2002). Exploring complex phenomena: Grounded theory in students affairs research. Journal of College Student Development, 43(2), 173-183.

da Silva, A. M. (2014). Upon the prevalence of English on billboard advertisements: Analysing the role of English in Indonesian contexts. TEFLIN Journal, 25(1), 33-61.

Fieldhouse, P. (Ed.). (1995). Food and nutrition: Customs and culture. Dordrecht: Springer Science.

Food Safety and Standards Authority of India. (FSSAI) (2011). Food Categorisation, retrieved 12 December 2015, from: fssai.gov.in

Grantham-McGregor, S., Cheung, Y.B., Cueto, S., Glewwe, P., Richter, L., Strupp, B., \& The International Child Development Steering Group. (2007). Development potential in the first 5 years for children in developing countries. Lancet, 369 , 60-70.

Goulding, C. (1999). Grounded theory: Some reflections on paradigm, procedures and misconceptions. Working paper series, WP006/99, Wolverhampton: University of Wolverhampton. [verified 24 May 2006]. Retrieved from: http://www.wlv.ac.uk/PDF/uwbs_WP00699\%20Goulding.pdf

Julia, M., Van Weissenbruch, M.M., Delamarre-van de Waal, H.A., \& Surjono, A. (2004). Influence of socio-economic status on the prevalence of stunted growth and obesity in prepubertal Indonesian children. Food and Nutrition Bulletin, 25(4), 354360.

Julia, M., Van Weissenbruch, M.M., Prawirohartono, E.P., Surjono, A., \& Delamarre-van de Waal, H.A. (2008). Tracking for underweight, overweight and obesity from childhood to adolescence: A 5-year follow-up study in urban Indonesian children. Hormone Research in Paediatrics, 69(5), $301-$ 306.

Kallen, J. L. (2010). Changing landscapes: Language, space and policy in the Dublin linguistic landscape. In: A. Jaworski \& C. Thurlow (Eds.). Semiotic landscapes: Language, Image, Space. (pp. 41-58). Chennai: MPG Books.

Landry, R. \& Bourhis, R.Y. (1997). Linguistic landscape and ethnolinguistic vitality: An empirical study. Journal of Language and Social Psychology, 16(1), 23-49.

Macalister, J. (2012). Language policies, language planning and linguistic landscapes in Timor-Leste. Language Problems and Language Planning, 36(1), 25-45.

Presiden Republik Indonesia. (2004). Government regulation of the Republic of Indonesia No. 28/2004 on food safety, quality and nutrition. Retrieved 10 May 2018 from:

http://codexindonesia.bsn.go.id/uploads/download/ PP_28-04\%20English.pdf

Rangan, A., Flood, V., Denyer, G., Webb, K., Marks, G., Gill, T. (2012). Dairy consumption and diet quality in a sample of Australian children. Journal of the American College of Nutrition, 31(3), 185193.

Rangan, A., Kwan, J., Louie, J., Flood, V., \& Gill, T. (2011). Changes in core food intake among Australian children between 1995 and 2007. European Journal of Clinical Nutrition, 65(11), 1201-1210.

Reagan, T. (2002). Language, education and ideology: Mapping the linguistic landscape of U.S. Schools. Westport, CT: Praeger Publishers.

Shohamy, E., \& Gorter, D. (2008). Linguistic landscape: Expanding the scenery. Place: Taylor $\&$ Francis.

Tafoya, S.M. (2002). The linguistic landscape of California schools. California Counts: Population Trends and Profiles, 3(4), 1-15.

Taylor-Leech, K.J. (2012). Language choice as an index of identity: Linguistic landscape in Dili, TimorLeste. International Journal of Multilingualism, 9(1), 15-34. 